\title{
Financial Innovation and Health Emergencies the Role of Crowdfunding Platforms in Italy
}

\author{
Valeria Roncone \\ Assistant professor of Financial Market and Institutions \\ Department of Economics, Management and Business law \\ University of Bari "Aldo Moro" \\ Largo Abbazia S.Scolastica, 53, 70124 Bari \\ Italy
}

\begin{abstract}
Crowdfunding is a collective financing tool for projects of various kinds that in recent months has shown incredible ability to support the financial needs of the Italian health sector following the crisis triggered by the COVID-19 health emergency. The work analyses the contribution of crowdfunding platforms to overcoming the financial needs of the various health facilities operating in Italy and concludes with the conviction that this tool can be considered fully among the various sources of financing to which the health system, especially the national one, can permanently refer.
\end{abstract}

Keywords: financial innovation, crowdfunding, Italian health system, COVID-19.

\section{Introduction}

The epidemic that has afflicted the entire planet for months and the abrupt halt of almost all economic activities and those typical of everyday life has inevitably led to reflect on the gravity of the current situation and on the questions raised by this and on the consequences of the same for the entire economic system.

We are facing new and unsettling events that have affected the entire globalized, rich and industrialized world, typically convinced that they can face any kind of emergency: political, economic or health. However, the epidemic has impacted on every aspect, forcing us to review habits of life and social relations, highlighting critical issues and therefore the need for interventions aimed at improving both the health conditions of the country and economic activities.

Of course, public health was particularly affected by this situation. In recent decades, the latter has been the subject of huge cuts in personnel spending, investments in medical equipment and for pharmacological research which have led to an evident weakening in terms of efficiency and quality of the public national health system to the advantage of expansion and strengthening of the private sector which, however, as events show, remains completely lacking in those skills useful for dealing with an emergency of this type.

The health emergency underway in Italy and in the rest of the world has led to a wave of solidarity that saw in its initial phase the birth of numerous fundraising in favor of hospitals, which found themselves in a moment of extreme need of machinery and additional personnel, as well as in support of the economic needs of families in difficulty.

The relentless commitment of doctors, nurses and healthcare personnel and the need to equip wards with materials to treat patients has seen the support of many people through online donations. The coronavirus triggered a solidarity marathon that involved thousands and thousands of Italians thanks to crowdfunding, making the famous solidarity sms obsolete, overwhelmed by the controversies of recent years ${ }^{1}$.

The thousands of campaigns activated to deal with the socio-health emergency had a single common denominator: crowdfunding platforms.

Crowdfunding takes place mainly on technological platforms that operate with the aim of finance a particular project by many lenders. For example, there are over three thousand fundraising campaigns hosted on GoFundMe (which is one of the best known and most used platforms), in the world, in support of hospitals and associations fighting COVID-19. Over two hundred those launched only in Italy.

The Italian Eppela has welcomed many small and large projects to be supported, from aid to voluntary associations that take care of the sick, to hospitals, to support for premises that are now closed due to the health emergency.

${ }^{1}$ Source: www.repubblica.it 18june 2018; www.ilsole24ore.it 24 september 2017; www.ilmessaggero.it 4 september 2019. 
To date, however, awareness of the correct dynamics of this type of fundraising still seems reduced, especially in the context of public realities, with the risk that many of the donations do not reach the final beneficiary and that, due toaccreditation and collection, funds are returned to donors, frustrating the efforts made ${ }^{2}$.

From the previous considerations arises the objective of this work which aims to provide insights on the functioning of crowdfunding platforms. Understanding the functioning and knowing the business models of this particular form of financing could contribute to a better understanding of this market and to better appreciate its potential.

This work is structured as follows: section 2 focuses on the key concepts related to crowdfunding; section 3 describes the different business models of the phenomenon in question including: donation-based, reward-based, lending-based and equity-based and the related regulatory framework and highlights market data relating to the national context; section 4 describes the main characteristics of crowdfunding platforms; section 5 focuses on the role that these platforms, especially the donation and reward-based ones, played during the COVID-19 emergency period; section 6 describes the first steps in the development of a health crowdfunding; section 7 concludes.

\section{Crowdfunding: key concepts}

The crowdfunding theme refers to a change in the methods of financing entrepreneurial projects compared to the more well-known forms of fundraising used so far.

The innovative scope of crowdfunding always assumes great emphasis in moments of crisis: we recall, in fact, the years of the recent financial crisis, in which it began to emerge and to capture the attention of scholars following the economic tightness and great difficulties, of individuals and companies, in finding financial resources; and the current moment of great health emergency that sees the multiplication of crowdfunding campaigns activated mainly to economically support health and private structures.

Crowdfunding has proved to be a tool capable of mitigating the criticalities deriving from the lack or insufficiency of financial resources and of constituting a sort of alternative to classic forms of financing, almost a challenge to traditional financial players (Rubinton BJ, 2014) and potentially useful to temporarily lighten an economy so heavily damaged by the events of recent years and by the current condition.

The definitions provided for the term crowdfunding are numerous and very similar (Estelle Arolas et al. 2012; Kleeman et al. 2008), probably that of De Buysere et al. is the most used.

"Crowdfunding can be defined as a collective effort of many individuals (the crowd) who organize and pool their resources to support the efforts initiated by other people or businesses. This is usually done with the help of the Internet. Individual projects and businesses are thus financed with small contributions from a large number of individuals, thus allowing entrepreneurs and business owners to use their social networks to raise capital "(De Buysere et al. 2012) .

However, it is also possible to find other more recent definitions such as that of Pais et al .: "A form of participation (financial, but not only) of the (social) network and through the network (Internet) in a project that is characterized by : completed planning; freedom of choice of the project and the designer, conveyed through reputational mechanisms; transparency of the funds raised "(Pais et al. 2014).

At this point it is possible to identify the constitutive elements of the phenomenon in question:

1. The crowd or multitude of people who contribute financial resources. Consumers who contribute financially to the realization of an entrepreneurial project can also be considered as "working consumers", that is subjects who become part of the production process and create value, whose capabilities can be considered as precious goods, which are integrated into corporate structures and whose actions can be monitored as if they were real employees.

2. Fund-raising which is the final goal of the whole process.

3. Internet and the development of web 2.0 technologies. The latter constitutes a fundamental prerequisite for the development of crowdfunding of which social innovation, understood as the development and implementation of new ideas (products, services or organizational models) that meet social needs and create new forms of relationship and collaboration, is one of its pillars.

The concepts of innovation and sociality (Hong et al. 2018; Saxton et al. 2015) fit perfectly with the phenomenon under consideration which, thanks to the elimination of the traditional barriers of financial investment, manages to make the creativity of the individual citizen collide and of the promoter of the initiative / entrepreneur and to ensure that they can find their realization and translate into products and services.

\footnotetext{
${ }^{2}$ Source: www.assif.it. However, it should be noted that thanks to the Cura Italia Decree of 17 March 2020, even public hospitals have had the opportunity to directly raise funds from private individuals.
} 
Crowdfunding completes the process that characterizes social innovation (Furlani et al. 2012): an individual who discovers a new social need develops a possible solution to its satisfaction, submits it to the crowd who choose whether to finance it or not and, in the case of success, develops it on a large scale and offers it to the entire market.

\section{Business models, regulatory framework and market data}

In recent years, crowdfunding has grown rapidly in parallel with the equally rapid development of technology and the growth of social media that have made it much easier to reach large numbers of people at reduced costs. Fundraising is facilitated thanks to the use of platforms which, based on the principles of collaboration and sharing, manage transactions by evaluating projects before presenting them to the public (Pierrakis et al. 2014).

From the analysis of the various crowdfunding platforms currently existing globally, it is possible to identify general operating models:

1) The donation based model ${ }^{3}$ (ex. Gofundme) provides for the possibility of donating sums of money to support a specific cause without receiving any reward in exchange.In this case, the lenders who access the dedicated platforms will view the fundraising campaigns active within and will be able to choose which of these to support. The essence of this model consists in the precise desire to make a contribution in order to participate in the implementation of projects aimed at social, cultural, environmental, welfare purposes and so on. In fact, philanthropic motivations are often in fact, and the existence of a good cause is the main driving force that drives people to support and support social projects, thus pushing benefactors to offer the necessary sums to complete the campaigns.

In this model, therefore, the concept of sociality linked to something tangible and real finds its maximum expression. In this case, crowdfunding acquires a very high social and community value if we think about what is the ultimate goal of a donation campaign.

It is important to highlight how non-profit organizations, those organizations that are not for profit, use this model of microfinance. The latter reinvest the profits for mainly organizational purposes.

The Italian legal framework on donation crowdfunding refers exclusively to the Civil Code which, in art. 769, defines donations as a liberal and conscious act of one party in favor of another without necessarily expecting a material benefit or reward in return. Specifically, an act of liberality occurs when a subjective element and an objective element occur, namely:

- the donor must be moved by the so-called animus donandi (subjective element);

- thedonee must, through the donation, enrich himself (objective element).

2) The reward-based model, the very first ${ }^{4}$ form of crowdfunding and probably the most used today with an important number of platforms active in our country, provides for the possibility of receiving a reward proportionate to the donation and which, generally, coincides with a product or a service ${ }^{5}$. In this type of collection, lenders are generally often particularly active in determining the characteristics of the asset to be created by playing an active role in starting the production of the same and allowing the sponsors of the campaign to understand the future appreciation of the market for that product or service. Crowdfunding is configured in this case more as a marketing tool than a source of capital, allowing producers to evaluate the interest in potential products, and is therefore particularly suitable for start-ups who want to launch a new product on the market (Sayedi et al. 2017; Belleflamme et al. 2015).

The platforms that operate according to this model do so by following two types of clauses: a) all or nothing: according to which the amount of bids collected for a given project are returned to individual investors if the applicant fails to accumulate the full amount required, by default, for the campaign. Among the platforms that have adopted this model, the most famous are the Italian Produzioni dal Basso, Eppela, Uelele (Italian by adoption but born in France in 2010), Kickstarter and Indiegogo (american platforms but operating in our country: the first from 2015, the second from 2016).

\footnotetext{
${ }^{3}$ This model, together with the reward and royalty-based model, belongs to the defined category of "non-profit crowdfunding". Therefore, it is not surprising that non-profit organizations are the ones who mainly use the donationbased model. In addition, donations to bodies set up in the form of non-profit organizations (non-profit organizations of social utility), may allow supporters to benefit from some tax relief as provided for in Article 14 of Legislative Decree 35 of 14 March 2005.

${ }^{4}$ The first platform to launch an online fundraising campaign in Italy according to the reward model was Produzioni dal Basso in 2005. Produzioni dal Basso began operating long before the term crowdfunding was coined (born between 2008 and 2009).

${ }^{5}$ The different types of rewards can consist of: copies of the product created, participation in the project to be financed, awards, etc.
} 
b) Take it all. This clause, as opposed to the first less widespread and usable for projects mainly of a social nature, provides that the applicant still obtains the amount collected at the end of the crowdfunding campaign regardless of whether or notof the predetermined target, therefore the promoter will not be forced to return the investment to the crowdfounder who adheres to the initiative as he believes in its success on the market and, consequently, in the fact that he will be rewarded for the trust placed in the program (for example, Indiegogo and Boomstarter are platforms that operate in this way).

The regulatory texts of the model in question are different according to the different types into which reward-based crowdfunding is divided and are respectively: the Civil Code art. 793 for modal donation; the Consumer Code for pre-order and again the Civil Code art. 2549 etseq for profit sharing or royalty based.

3) The lending-based or peer to peer lending (p2p) model constitutes a microloan system between individuals. Peerto-peer lending can be understood as a transaction that takes place online directly between individuals without the intermediation of traditional financial institutions (pursuant to Article 106 of the Consolidated Banking Act): a group of people lends small amounts of money to other subjects, chosen on the basis of their public profiles on the platform and all with a rating. Against the loan, a more favorable interest rate is perceived than that proposed by traditional financial intermediaries and instead the recipient of the loan pays a slightly higher interest rate than medium-term loans but lower than the normal credit rates at consumption to which social lending is assimilated. From a regulatory point of view, the references for this model are two: the Civil Code with regard to the loan agreement which is technically configured as a loan agreement pursuant to art. 1813 and 1815; Resolution $584 / 2016$ of the Bank of Italy laying down provisions for the collection of savings by parties other than banks with regard to the general theme of crowdfunding ${ }^{6}$

The social lending platforms Smartika, Prestiamoci and BorsadelCredito are famous.

4) The equity-based model is a mechanism that attracts micro investors to a project, remunerating the investment with a shareholding in the sponsoring company of the project which generally defines a period of time and a target sum. The target is then divided into thousands of equal shares which are offered through the platform in the form of fixed price shares. The offers go on until the target is reached: after that, the actual investment phase begins. The launch of a campaign of this type allows to obtain a great visibility, and the relationships and contacts that are produced still create value for the company by strengthening the group of stakeholders. In this way, the opportunity was created for companies to collect, without intermediation, the financial resources necessary for the realization of an industrial plan, based solely on the proposed project and on their own credibility; an important paradigm shift in the start-up and development phase of a business. However, since it is in any case a real investment in the capital of companies, these cannot fail to make assessments about the terms of the operation linked to the share of capital offered to the public, the price of the shares, the costs of the operation and the preparation of a business plan.

The model in question was the first subject to specific legislation probably because there are proposals for the purchase of company shares that involve highly risky and medium-long term investments for the investor.

In particular, Italy was the first country to adopt specific legislation on equity crowdfunding, unlike the other European countries where the Supervisory Authorities limited themselves to the publication of illustrative documents containing the characteristics of crowdfunding, the risks for the investor as well as existing legislation in which to frame the phenomenon. In fact, in Europe, the various portals operate in different ways, under the supervision of the individual Authorities and by ESMA (European Financial Instruments and Markets Authority) which in September 2012 deemed it appropriate to publish an information document for investors in which the pitfalls of online investment are highlighted. To date, despite a high heterogeneity of business models, there is no harmonized regulation in Europe.

In Italy, the Growth Decree bis, or the Law Decree of 18 October 2012 n.179 was the starting point for crowdfunding in general and equity crowdfunding in particular. By modifying the Consolidated Law on Finance (Article 1, paragraph 5-novies; Article 50-quinquies and Article 100-ter), the Decree aimed at relaunching the competitiveness of the Italian business system through numerous interventions aimed at stimulating the innovation and financing for small and medium-sized enterprises (SMEs). In particular, the new regulations concerned those newly or recently established companies oriented to the production of innovative or highly technological products and services (innovative start-ups).

\footnotetext{
${ }^{6}$ Section IX of Resolution no. 586 of 2016 of the Bank of Italy defines lending crowdfunding as social lending, that is "a tool through which a plurality of subjects can request from a plurality of potential lenders, through online platforms, repayable funds for personal use or to finance a project ". 
Looking now at the market data relating to Italy, the recent Starteed ${ }^{7}$ report confirms a considerable growth trend in crowdfunding in all its expressions for 2019. In particular, more than 160 million euros $(+59 \%)$ were raised, bringing the amount raised up to 2019 starting from 2015 to more than 442 million euros.

All business models recorded a positive trend, although the driving forces were equity and lending crowdfunding, which were able to take advantage of the very favorable regulatory environment. For these two models, the proliferation of platforms (Trusters, Walliance, Housers, CrowdEstate) also in the real estate sector which, thanks to the prospects of secure and short-term returns, have satisfied the interest of many investors (Cohen 2016; Matthiesen et al . 2017; Jiang et al. 2019).

In relation to the type of crowdfunding, the 2019 data can be summarized as follows:

-donation and reward: the collection, which was concentrated on a few platforms ${ }^{8}$, amounted to 16 million euros (+ $28 \%$ compared to 2018). The leap is due to the strengthening of community engagement experiences and Open Innovation and Corporate Social Responsibility initiatives(CSR). The issues that recorded the most interesting results were: humanitarian emergency, non-violence against women, medical care.

- equity: amount raised equal to more than 68 million euros (+114\% compared to 2018$)^{9}$;

- lending: deposits of more than 78 million euros ${ }^{10}$ ( $+49 \%$ compared to 2018).

As already anticipated and as can be deduced from the data, the positive trend is mainly driven by lending crowdfunding followed by the equity type method, thanks to the favorable regulatory environment existing in Italy, as already stated.

While equity crowdfunding and, to a minimum, social lending can count on a legal framework that monitors fundraising while protecting the investor and his money, the same cannot be said for the other standard types (donation, invoice, pre-purchase, real estate, rewards and royalties) for which it is customary to refer to the existing regulation for similar financing methods.

\section{General characteristics of crowdfunding platforms}

Among the actors of crowdfunding, in addition to the proponent and crowdfunders, a preponderant role is played by the platforms that constitute virtual places with the aim of collecting financial resources and encouraging interaction between the other two types of subjects involved in the project. Therefore, thanks to the platforms, any proponent, whether a private individual, an association or a company, will be able to publish their project which will subsequently be viewed by the lenders.

The characteristic aspects that unite the different types of platforms can be summarized in (Agrawal et al. 2011):

1. removal of any communication barrier at a geographical level;

2. possibility of participating in projects even with small amounts;

3. provision of information on the parties to the transaction and useful tools for direct interaction between them without the aid of specialized intermediaries.

On the basis of these characteristics it is possible to believe that crowdfunding platforms operate according to the multi side market model (Hagiu et al. 2015) which facilitates the meeting between two or more parties with opposing needs, generating value and guaranteeing an increase in size and visibility to the platform as the number of users increases.

In general, when the sponsor of a project or a collection decides to rely on a crowdfunding platform, in order to reach the largest number of lenders, he must take into consideration a series of elements, the most important of which are:

a. The vocation of the platform: that is, whether it is a generalist or sectorial platform. The platforms defined as generalist welcome projects of various kinds relating to different thematic areas or sectors of the economy. The sectorial platforms instead group together campaigns related to a specific area of interest.

\footnotetext{
${ }^{7}$ Starteed is a crowd-company that was created with the aim of promoting innovative financing processes through the involvement of the crowd.

${ }^{8}$ The donation and reward crowdfunding platforms in Italy in 2019 were 51 of which only 29 were active. Those that have collected the most are: Produzioni dal Basso, Rete del dono, Forfunding, Eppela and Buonacausa (source: Starteed)

${ }^{9}$ There were 38 equity crowdfunding platforms in Italy in 2019, 24 of which were active. The ones that collected the most were: Mamacrowd, Crowdfundme, Two Hundred, Walliance and Backtowork24.

${ }^{10}$ There were 12 lending platforms in Italy in 2019, 10 of which were active. Those that collected the most were: October, Borsadelcredito, Soisy, Ethical Return and Prestiamoci.
} 
They are suitable for projects that aim at a specific target of supporters who will therefore be more inclined to finance the cause. For example, the American platform Kickstarter is dedicated exclusively to cultural or creative projects, while the Italian MusicRaiser concerns a specific sector: that of music.

However, platforms of this type, due to their sectorial nature, attract a specific audience and in most cases more limited than that of generic platforms.

b. The geographical scope of operation: which distinguishes national platforms which, welcoming campaigns regardless of the place where they have their roots and unfold their effects, can be both generalist and sectorial; and the local platforms which instead welcome projects that are destined to produce effects in a specific territorialgeographical area: region or locality. These platforms are mainly thematic; they can accommodate more than one sector, and are aimed at improving the conditions of the economic and social fabric by stimulating the community through participatory economy, thanks to events and activities that aim at the improvement of the community itself.

c. The onerousness of the portal (the required commissions): in general, it is said that a platform applies commissions if the crowdfunding site withdraws a percentage of all the money raised. Most platforms retain a percentage of the budget collected from the campaign, these are percentage commissions that vary from a minimum of $2 \%$ to a maximum of $25 \%$ although usually the average fluctuates around $5 \%$. There are platforms that apply commissions only if the goal is achieved; in others, the commissions vary depending on whether the platform adopts the all or nothing or take it all model, usually higher commissions are expected if the user does not reach the set goal. The commissions of the platforms must also be added to those for banking transactions, which in some cases can represent a profit margin for the platforms themselves. Table 1 shows the rates applied by some of the most important crowdfunding sites.

d. The duration of the campaign: the average of crowdfunding projects is about 45 days. Shorter campaigns have a better chance of reaching their financial goal and benefiting from good communication dynamics. In any case, the maximum is 90 days ${ }^{11}$.

\section{The role of donation and reward based crowdfunding platforms in the COVID-19 emergency.}

If we look at the past events related to the recent financial crisis and its consequences for all world economies and now the great socio-health upheavals related to the Coronavirus pandemic in progress, we cannot help but notice how the crowdfunding tool and its platforms have taken on a significant weight in contributing financially to sustenance and overcoming emerging difficulties. In other words, it is possible to affirm how crowdfunding in cases of great difficulty is confirmed as a useful and valid financial tool, simple and immediate that meets the economic and financial needs deriving from emergencies of various types.

Crowdfunding is in a moment of great diffusion and is providing valuable help: since the first days in which the ongoing health emergency appeared in all its gravity, numerous fundraising campaigns in support of crowdfunding portals have multiplied structures and organizations involved in this emergency and the related and complex social situation $^{12}$.

Celebrities from the world of entertainment, sport and influencers have transmitted and promoted the campaigns through their social networks, giving life to a real race for donations. The most supported campaign, which to date has become the most important crowdfunding fundraiser ever carried out in Europe, was the one promoted by the Ferragnez, or by the couple of celebrities formed by Chiara Ferragni and her husband Fedez, who have decided to promote the "Coronavirus, let's strengthen intensive care" project on the GoFundMecrowdfunding platform, raised in favor of the San Raffaele Hospital in Milan with the aim of strengthening the intensive care unit.

Following the success of the campaign, hundreds of other collections for hospitals throughout Italy flourished from the initiative of ordinary citizens, also lacking structures sufficiently prepared to respond to the request for hospitalization of people affected by the Virus, among many we remember the projects "Cesvi for the Bergamo hospital", "Let's give a hand to the Cotugno of Naples" and "Strength and Heart for Florence".

\footnotetext{
${ }^{11}$ Source: www.ulule.com

A survey conducted by the Indiegogo platform on over 100,000 campaigns published on its platform revealed that 30-day campaigns work better, this time limit in fact allows the community to have plenty of time to support the collection and ensure its success. Of all the campaigns monitored and which achieved their objectives, nearly a third (30.5\%) conducted a campaign between 30 and 39 days. It is then necessary to consider how much time can be spent following the campaign. You have to be able to build interest, maintain momentum and keep the audience engaged. If you find that 30 days isn't enough, you can extend the campaign to 60 days. But it should be borne in mind that this option should be considered more like running two 30-day campaigns, rather than one of 60. Considering the duration in this way could work better, both in terms of marketing and resource allocation. (Source: www.crowdfundingbuzz.it)

${ }^{12}$ Source: www.italianonprofit.it/donazioni-coronavirus/
} 
With more than 700 collection campaigns, in Italy alone, crowdfunding has proved to be an effective tool to allow citizens to offer their active, immediate and above all transparent contribution to the organizations involved in the fight against the virus.

At this moment the platforms play a very delicate and essential role in guaranteeing the safety of their users and transparency in the management of the funds raised by individual campaigns. Given the specificity of the needs in place, the platforms most, if not exclusively, involved are those of the donation and reward based type.

A recent survey (April 2020), conducted by the European Crowdfunding Network among the various European crowdfunding platforms with the aim of measuring the impact of COVID -19 on their work, highlights that among the different types, those of the donation and reward type have experienced a low negative impact, compared to equity and lending platforms, both in terms of incoming flows and on new campaigns and on those already in place, highlighting a growing interest from investors in financing opportunities related to COVID-19 and in particular to " launch of new social and solidarity initiatives linked to the health emergency (Figure 1).

As for Italy, as of May 2020 there were 11 active donation platforms, 23 reward ones and 12 hybrid ones ${ }^{13}$. Table 2 shows some examples.

The platforms that collected the most in 2019 were: Produzioni dal Basso, Rete del dono, Forfunding, Eppela and Buonacausa with a success rate of approximately 14,800 donation and reward campaigns of $51 \%$ which corresponded to an average collection of $€ 8,000$ and an average donation of $€ 150^{14}$.

As regards the year 2020, almost half a billion euros from private individuals, individual institutes, foundations, large NGOs and crowdfunding platforms were disbursed for the financing of healthcare facilities and the purchase of medical devices.

Among the platforms listed above, the following were particularly active: Gofundme, Forfunding, Rete del Dono and Tinaba (table 3).

Gofundme with over 15 million euros raised through 600,000 donations. The platform was accused, among other things, of unfair commercial practice by the Antitrust because the site interface can mislead the user and pay an additional tip to the platform itself (which can reach 10\%). Another 3,027,925 euros went through Forfunding (the BancaIntesa platform, which has no commissions) with a total of 16,236 donations (including 420,273 euros for the Bergamo field hospital promoted by Cesvi). 1,693,796 euros come from Rete del Dono, which, for fundraising aimed at supporting macro-emergencies - that is, situations of great danger for people, goods, structures and the environment exposed to catastrophic damage and that require extraordinary interventions (such as the current moment) - applies a fee of 3\% instead of 5\%. About 300 thousand euros for the Tinaba platform, the only one with zero commissions.

\section{The development of healthcare crowdfunding}

Since the 90s when it was a niche phenomenon, crowdfunding has become a fundamental tool for obtaining financing related to the social sphere.

From the foregoing paragraphs, it emerged the ability of crowdfunding platforms to contribute to solving the shortage of funds and financial difficulties in the medical health sector that arose at the beginning of the spread of the COVID-19 pandemic. However, the crowdfunding tool may not only be considered as a transitional solution adopted only in the event of a health emergency, but it could also in fact be part of the financial instruments used to tackle the chronic lack of financial resources in our health system. The arguments are based on the daily experience that each of us experiences on social networks able to offer a powerful contribution to the knowledge and publicity of such campaigns and the consistent number of fundraisers aimed at helping patients in supporting costs for therapies, especially those not available in the country of residence. Leader in this field is Gofundme who, with more than 250,000 campaigns a year and more than 500 million euros raised at no cost, leads the ranking of online campaigns for medical expenses. Also important isAescuvest which is the only crowdfunding platform in Europe active in the healthcare sector. Specifically, it is a German fintech that offers marketing services and a fundraising platform for startups and growing companies belonging to the healthcare sector, both in Germany and in Europe.

Thanks to the collaboration with the European Institute of Innovation and Technology (EIT Health), it comes into contact with the most interesting startups and with European organizations operating in the field of health care pharmaceutical companies, research institutes, medical universities etc.

\footnotetext{
${ }^{13}$ Hybrid models provide for the union of more models than those described in the text. The value of these models is inherent in the possibility of intercepting the greatest number of donors.

${ }^{14}$ Source: Starteed
} 
Companies that raise funds through the platform are selected by a committee made up of professionals. The initiatives supported are those carried out in the biotechnology and pharmaceutical fields, in the digital sector (always aimed at health) and relating to projects that bring progress in medical technology.

Not falling within the type of donation or reward based platform, in this case Aescuvest investors face a real business risk which has as a counterpart a potentially high return that derives from an industry such as healthcare which is one of the most important and growing economic sectors, capable of offering great opportunities ${ }^{15}$.

Finally, noteworthy is the "MSD CrowdCaring" initiative (and here we return in a reward dress) proposed, in 2019, by MSD, a pharmaceutical company present in Italy for over 60 years, and Eppela, an Italian reward crowdfunding platform, which aims to financing of the best projects in some aspects of the health sector: correct health information, digital health, simplification of treatment paths, improvement of the quality of life of patients and prevention. The initiativehas seen the funding, through four 40-day campaigns, of projects in four specific health areas: vaccines, fight against cancer, diabetes and HIV.

\section{Conclusions}

In recent years, crowdfunding has proved to be a tool full of potential, capable of stimulating innovation, business growth and in this last period also the well-being of the community, earning a worthy position in the financial system.

Born in the early 2000s, it drew great impetus from the climate of distrust towards the financial world that had resulted from the international financial crisis. The term crowdfunding indicates a form of financing, having different purposes, which is generated on the web, on the so-called online platforms, thanks to the direct involvement of a multiplicity of individuals. It sees a series of business models classified according to the financial return recognized to the investor such as: donation based crowdfunding, reward based, social lending and equity crowdfunding.

The development of the phenomenon in question in recent years has certainly been exponential, confirming the North American market as the leader in the sector. The Italian phenomenon is smaller than the American one, both in terms of the number of platforms and the number of projects presented and financed and the average volumes of resources brokered by the platforms. Although the Italian market, on the one hand, has proved inferior in terms of resources collected, on the other it is a market at the forefront from a regulatory and regulatory point of view. The Italian legislator, the first in Europe, has in fact regulated the crowdfunding phenomenon placing the emphasis exclusively on equity crowdfunding and the financing of innovative start-ups.

The innovative scopes of the tool and its benefits have had great prominence in our country at this time of difficulty linked to the coronavirus pandemic. Therefore, it seemed interesting to focus on the role played by crowdfunding platforms, especially those of the donation and reward based type, in supporting the emergency created following the widespread diffusion of COVID-19 in Italy and around the world.

Given the serious emergency situation in our country, it was possible to observe, from the first days of crisis, the birth, first on the initiative of famous influencers and subsequently of ordinary citizens, of countless fundraisers in support of the structures and organizations involved in the health emergency in order to be able to implement the services necessary to deal with the situation. The leading platform in this period was certainly the American platform GoFundMe which with more than 3300 collections (not only in Italy) has collected more than 15 million euros.

In a moment, like the current one, of strong insecurity in which the coronavirus has brought serious and unexpected consequences all over the world, forcibly upsetting people's habits, recording a drastic drop in consumption, great instability in the financial markets, and great difficulties healthcare, crowdfunding, thanks to the possibility of financing charitable initiatives, has been confirmed as a valid financial tool by accelerating access to capital and minimizing bureaucratic difficulties often guilty of delays in aid. The platforms with their intuitiveness and simplicity of operation have allowed everyone to participate according to their own possibilities, reaching truly significant collection objectives in favor of the community, playing an important social role and helping in dealing with the health emergency we are experiencing. The great attention paid to this financing instrument and the important benefits it brings leads to hypothesize the possibility for the latter to be able to fully qualify as one of the various sources of financing to which the health system, especially the national one, can refer permanently.

\footnotetext{
${ }^{15}$ We must also consider the risk of failure of the initiative, a hypothesis that is anything but rare, aggravated by the fact that we are talking about startups and very young companies. It means that the expected return is not guaranteed and may be less than your invested amount. Equity crowdfunding generally attracts retail investors because it offers interesting and stimulating projects with higher earnings prospects than other types of investments.
} 
Tables and figures

Table 1- The costs of the main crowdfunding platforms

\begin{tabular}{|l|l|l|}
\hline Platform & Collection fees & $\begin{array}{l}\text { Fees related to the payment } \\
\text { method }\end{array}$ \\
\hline Gofundme & $0 \%$ (in the case of a single & $2,9 \%+0,25 €$ per transaction \\
\hline Fundrazr & $\begin{array}{l}0 \% \text {.a. } \\
\text { individual - a voluntary } \\
\text { contribution is expected); 5\% (in } \\
\text { case of organization) }\end{array}$ & \\
\hline Crowdrise & $3 \%-5 \%$ & $2,4 \%-2,9 \%+0,30 \$$ per transaction \\
\hline Fundly & $4,9 \%$ & $2,9 \%+0,30 \$$ per transaction \\
\hline Kickstarter & $5 \%$ & $3 \%+0,20 \$$ per transaction \\
\hline Indiegogo & $5 \%$ & $3 \%+0,20 \$$ per transaction \\
\hline Forfunding (IntesaSanpaolo) & $0 \%$ & $0 \%$ \\
\hline Rete del Dono & $5 \%+$ VATonly if the beneficiary is & $1,8 \%+0,35 €$ per transaction \\
& $\begin{array}{l}\text { a natural person; } 0 \% \text { in the case of } \\
\text { a non-profit organization }\end{array}$ & $\begin{array}{l}1,2 \%+0,15 € \text { (Visa/Mastercard) } \\
2,7 \%+0,25 € \text { (American Express) }\end{array}$ \\
\hline Eppela & $5 \%$ & $\begin{array}{l}n \\
\text { no. }\end{array}$ \\
\hline DeRev & $4 \%-9 \%$ & $\begin{array}{l}3,4 \%+0,35 \text { (Paypal) } \\
0,9 \%+0,20 \text { (Lemonway) }\end{array}$ \\
\hline Produzioni dal Basso & $3 \%-5 \%$ & \\
\hline
\end{tabular}

Source: websites of the individual platforms

Table 2 - Some examples of donation and reward based crowdfunding platforms active in Italy

\begin{tabular}{|l|l|l|}
\hline Platform & Business model & Sector \\
\hline 1Caffè & Donation & Generalist \\
\hline Forfunding (IntesaSanpaolo) & Donation & Generalist \\
\hline Gofundme & Donation & Generalist \\
\hline Insiemedoniamo & Donation & Social \\
\hline Rete del dono & Donation & Third sector \\
\hline Be Crowdy & Reward & Art and culture \\
\hline Eppela & Reward & Generalist \\
\hline Kickstarter & Reward & Generalist \\
\hline Indiegogo & Reward & Generalist \\
\hline Upspringer & Reward & Publishing \\
\hline DeRev & Hybrid & Innovation \\
\hline Produzioni dal Basso & Hybrid & Generalist \\
\hline Greenfunding & Hybrid & Green economy \\
\hline Proposizione & Hybrid & Generalist \\
\hline FundItalyee & Hybrid & Generalist \\
\hline
\end{tabular}

Source: personal elaboration

Table 3 - Fundraising in support of healthcare facilities and the purchase of medical devices (data April 2020)

\begin{tabular}{|l|l|l|}
\hline Fundraising on the web & Funding & Number of donations \\
\hline Platform & $3.027 .925 €$ & 16.236 \\
\hline Forfunding & $+15 \mathrm{mln} €$ & 600.000 \\
\hline Gofundme & $1.693 .796 €$ & 17142 \\
\hline Rete del Dono & $299.716 €$ & 1689 \\
\hline Tinaba &
\end{tabular}

Surce: Gabanelli M., DataroomCorriere della Sera, april 2020 
Figure 1. Impact of COVID-19 on the work of donation and reward based platforms (April 2020)
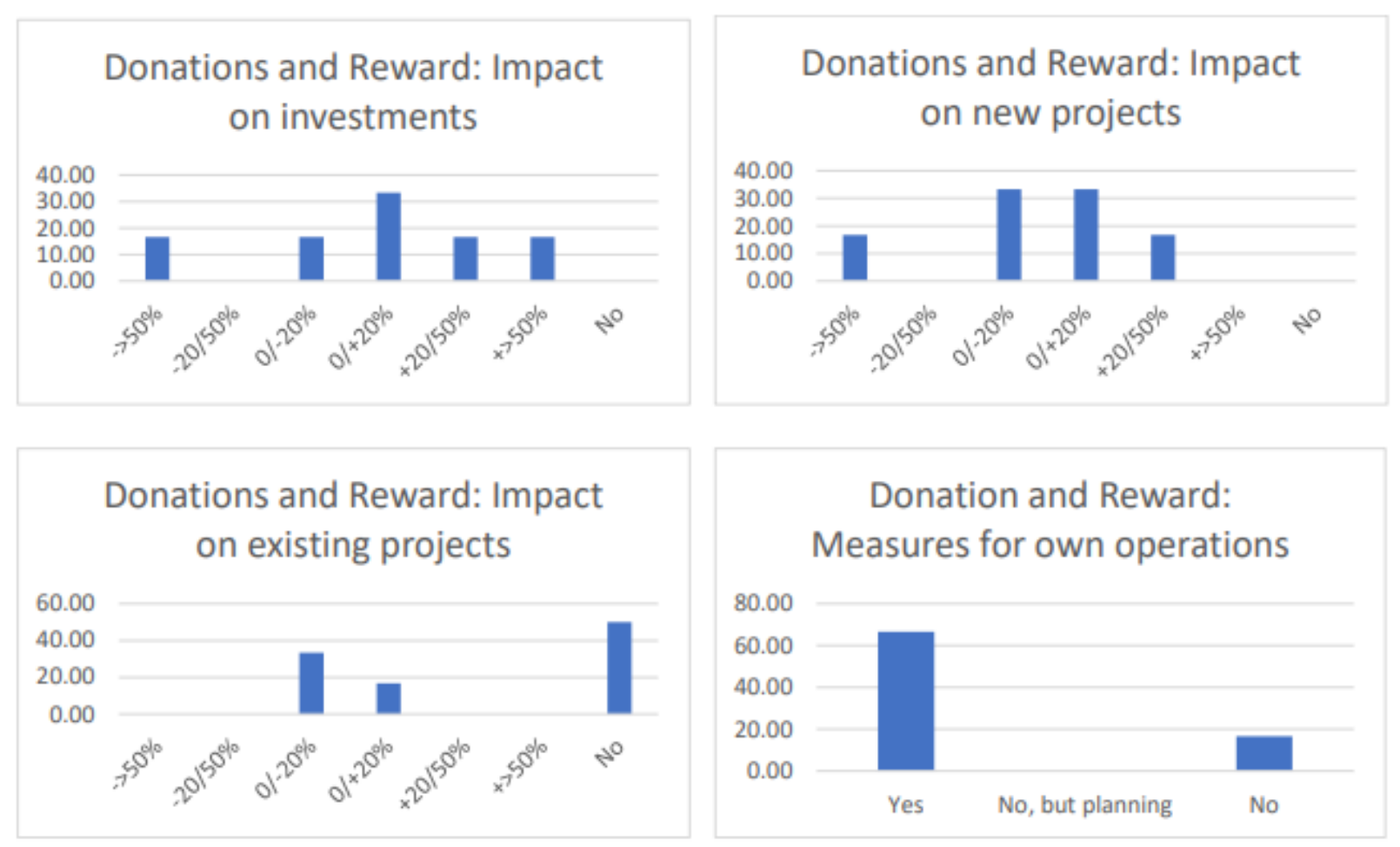

\section{Source: European Crowdfunding Network (www.eurocrowd.org)}

\section{References}

Agrawal J. K., Catalini C., Goldfarb A., (2011). The Geography of Crowdfunding, National Bureau of Economic Research, Working paper n. 16820, avaible: www.ssrn.com.

Belleflamme P., Lambert T., Schwienbacher A., (2014). Crowdfunding: Tapping the right crowd.Journal of Business Venturing, 29(5).

Belleflamme P., Omrani N., Peitz M., (2015). The economics of crowdfunding platforms, avaible: www.ssrn.com.

Boudreau, K. J., Lakhani, K. R., (2013). Using the crowd as an innovation partner.Harvard Business Review, 91(4).

Brabham D.C., (2008). Crowdsourcing as a model for problem solving: an introduction and cases.Convergence: the International Journal of Research into New Media Technologies 14:1.

Calveri C., Esposito R., Crowdfunding world 2013. Report, analisi e trend, report on line: www.derev.com.

Cohen J., (2016).A study on the history and functionality of real estate crowdfunding, on line: https://core.ac.uk/download/pdf/76391612.pdf.

Commissione Europea, (2013) Guida alla Social Innovation. On line http://europa.formez.it/content/guide-tosocial-innovation.

Commissione Europea, (2017). Il crowdfunding cosa è. Una guida per le piccole e medie imprese, on line: https://op.europa.eu/it/publication-detail/-/publication/d5e626ba-d7c8-11e6-ad7c-01 aa75ed71a1/languageit/format-PDF

De Buysere, K., Gajda, O., Kleverlaan R.,Marom D, (2012). A Framework for European Crowdfunding, $1^{\circ}$ edizione, www.crowdfundingframework.eu

Estellés Arolas, E.; González Ladrón-de-Guevara, F., (2012).Towards an integrated crowdsourcing definition.Journal of Information Science, vol 38, n.2.

Furlani A., Lutman F., (2012). Social innovation. Reti sociali: le nuove protagoniste dell'innovazione. Una guida pratica per le aziende italiane, Franco Angeli Editore.

Hagiu A., Wright J., (2015). Multi-side platforms, avaible: www.ssrn.com.

Hong Y., Hu Y., Burtch G., (2018).Embeddedness, Pro-Sociality, and Social Influence: Evidence from Online Crowdfunding, avaible: www.ssrn.com.

Jiang Y., Ho Y.-C., Yan X., Tan Y., (2019). When on line lending meets real estate: examining investment decisions in lending - based real estate crowdfunding, avaible: www.ssrn.com.

Kleeman F., Gunter Voss G. e Rieder K., (2008). Un(der)paid innovators: the commercial utilization of consumer work through crowdsourcing.Science, Technology \& Innovation Studies, 4:1, on line: https://core.ac.uk/download/pdf/46909382.pdf 
Matthiesen M.L., Steininger B.I., (2017), Financial Innovation: crowdfunding for the real estate market, avaible: www.ssrn.com.

Mejia J., Urrea G., Pedranza Martinez A., (2018). Operational Transparency on Crowdfunding Platforms: effect on donations for emergency response, avaible:www.ssrn.com.

Mollick, E., (2014). The dinamycs of crowdfunding.An explanatory study, Journal of business venturing, n.29, on line https://www.sciencedirect.com/science/article/pii/S088390261300058X

Pais I., Peretti P. \& Spinelli C.,(2014).Crowdfunding. La via collaborativa all'imprenditorialità, Milano, Egea Editore.

Pierrakis Y., Collins L., (2013). Crowdfunding a new innovative model of providing funding to projects and businesses, avaible: www.ssrn.com

Quaranta G., (2015). Crowdfunding. Il finanziamento della folla o dei “folli”?.Rivista di Diritto ed Economia dell'Impresa, Fascicolo n.5, Giappichelli Editore.

RubintonB.J., (2014). Crowdfunding: Disintermediated Investment Banking, avaible:www.ssrn.com

Saxton G.D., Wang L., (2015). The social network effect: the determinants of giving through social media, avaible: www.ssrn.com

Sayedi A., Baghaie M., (2017). Crowdfunding as a marketing tool, avaible: www.ssrn.com

\section{Web sources}

www.backtowork24.com

www.bancaditalia.it

www.borsadelcredito.it

www.consob.it

www.corrieredellasera.it

www.crowdestate.eu

www.crowdfundme.it

www.crowdrise.com

www.derev.com

www.eppela.com

www.eurocrowd.org

www.forfunding.intesasanpaolo.com

www.fundly.com

www.fundrazr.com

www.gofundme.com

www.housers.com

www.ilmessaggero.it

www.ilsole24ore.it

www.indiegogo.com

www.italiancrowdfunding.it

www.kickstarter.com

www.mamacrowd.com

www.prestiamoci.it

www.produzionidalbasso.it

www.rendimentoetico.it

www.repubblica.it

www.retedeldono.it

www.soisy.it

www.ssrn.com

www.starteed.com

www.trusters.it

www.twohundred.it

www.ulule.com 